\title{
What, not just salad and veg? Consumer testing of the eatwell week
}

\author{
Wilma S Leslie ${ }^{1, *}$, Jane Eunson ${ }^{2}$, Lorraine Murray ${ }^{2}$, Michael EJ Lean ${ }^{1}$ and \\ Catherine R Hankey ${ }^{1}$ \\ 'Human Nutrition, School of Medicine - GRI Campus, University of Glasgow, Room 22, 4th Floor, Walton \\ Building, Glasgow Royal Infirmary, 84 Castle Street, Glasgow G4 OSF, UK: ${ }^{2}$ Ipsos MORI Scotland, Edinburgh, UK
}

Submitted 6 December 2012: Final revision received 26 April 2013: Accepted 20 May 2013: First published online 28 June 2013

\begin{abstract}
Objective: To test the appeal of the eatwell week, a nutritionally balanced $7 \mathrm{~d}$ menu which satisfies nutritional guidelines of the Food Standards Agency in Scotland; determine the clarity and understanding of the main messages; and gather views on the usability and acceptability of the eatwell week resource format.

Design: Focus group discussions with consumers and health professionals.

Setting: Four locations across the UK.

Results: The eatwell week was considered realistic by consumers as it contained foods they recognised and already ate. A preconceived idea had been that there would be more fruit and vegetables and fewer 'treats'. Consumers found the recipes simple and lack of cooking skills was not an apparent barrier. However, the message of 'balance' was poorly understood. Consumers often lacked the knowledge to make informed substitutions in the week. Both the general public and some health professionals felt the menu contained too much carbohydrate. Health professionals felt it was unclear who the eatwell week was intended for and what purpose it served.

Conclusions: Use of familiar foods and the provision of simple, easy-to-follow recipes have the potential to overcome some barriers to healthy eating encountered by the general public and encourage improvements in dietary intakes. The eatwell week shows promise as a resource to facilitate implementation of the principles of the eatwell plate and supports government priorities and policies for health.
\end{abstract}

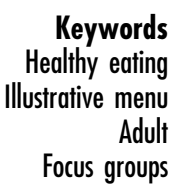

Public health approaches intended to encourage changes in food intake towards a healthier diet are numerous. Most rely on the provision of information in verbal and written form. The principal non-verbal public health tool for communicating information about healthy eating in the UK is the eatwell plate. However, dietary surveillance shows little improvement in population dietary intakes $^{(1-4)}$ and obesity prevalence continues to rise ${ }^{(3,4)}$, suggesting that individuals may have difficulty implementing non-quantitative healthy eating guidance depicted by the eatwell plate. There is also a widespread view that healthier diets are expensive and contain unfamiliar foods ${ }^{(5)}$.

With the aim of providing more structured guidance to assist individuals put eatwell plate information into practice, the Food Standards Agency (FSA) in Scotland commissioned the development of an eatwell week resource. The resource was intended to provide a detailed illustration of how a healthy balanced diet could look over the course of one week and assist individuals in planning their own meals. The resource includes a practical example of a $7 \mathrm{~d}$ menu which meets dietary targets of the UK Dietary Reference Values ${ }^{(6)}$. Energy provision was based on the average requirements of an adult woman $(\sim 8368 \mathrm{~kJ} / \mathrm{d}(\sim 2000 \mathrm{kcal} / \mathrm{d}))$. Supplementary advice was provided to aid the implementation of the menu. Data on commonly consumed meals in the UK were provided by Taylor Nelson Sofres and used to guide the menu development, the details of which have been published previously ${ }^{(7)}$.

Ipsos MORI Scotland, an independent research agency, carried out testing of the draft eatwell week with consumers, and also with health professionals who might use it in their work. The main aims of the work reported here were to test the appeal of the resource, determine the clarity and understanding of the main messages and gather views on the usability and acceptability of the format of the resource. These data would inform revisions to the final presentation of the eatwell week resource. 


\section{Methods}

\section{Focus group recruitment and participants}

Recruitment screening questionnaires were developed by Ipsos MORI Scotland, then reviewed and approved by the project reference group (FSA in Scotland and independent academics).

Consumer recruitment was undertaken by research recruiters working on-street or door-to-door in four locations throughout the UK (Table 1). It was felt that there was little point in testing the eatwell week with people who would have very little interest in such a resource and who would be very unlikely to use it, so potential participants were asked: 'Experts in nutrition are producing a menu of example meals and recipes that people can follow to ensure that they have a balanced diet over the course of a week. If you saw this somewhere, how interested would you be in trying it out?' Only those who said they would be 'very interested' or 'quite interested' were recruited. Potential recruits were also asked: 'Taking part in this research would involve trying out the menu that I have just described in between the two group sessions. Are you willing to do this?' Only those willing to try out the menu were recruited. People who were responsible for less than half of their household shopping, who prepared less than half of the evening meals in their household and people who typically ate fewer than four evening meals per week at home were also excluded.

Thirty-five adult consumers (eighteen female, seventeen male) from different demographic groups and with a range of cooking habits were recruited (Table 1). Across the groups, there were five participants from minority ethnic groups. The consumer groups met twice. In the first session they were introduced to the resource, discussed their initial reactions and were invited to try out the resource. In the second session, two weeks later, their experiences of using the eatwell week were discussed.

Recruitment of health professionals was undertaken primarily by telephone and email. One group comprised six health professionals including practice nurses, cardiac rehabilitation nurses and occupational health nurses working in Glasgow, Edinburgh and other parts of the Central Belt of Scotland (the group met in Falkirk). Another comprised seven community dietitians working in London. As with the consumer groups, two focus group sessions were planned for the health professionals and dietitians: one to be introduced to the resource and to discuss their initial reactions, and one a fortnight later to discuss their experiences of using the resource, if they had done so, with clients.

A third group, also based in London, comprised six health promotion professionals in a variety of roles relating to public health including health promotion community development/community food initiatives and major health charities. This group met only once as the participants did not have a client group with whom they might test the resource and it was their own views on the resource that were sought.

In addition to the focus groups, three in-depth interviews were undertaken with consumers with lower literacy levels, recruited through an adult literacy class in Scotland.

All participants were paid a gratuity for their participation. Oral consent was obtained from all participants at recruitment and again at the commencement of the focus groups. Ipsos MORI adheres to the Market Research Society's code of conduct and the ethical guidelines of the Social Research Association.

\section{Data collection and analysis}

With participants' consent, all focus group sessions and interviews were recorded and transcribed for analysis. The three researchers who conducted the groups/interviews read over the transcripts then met for an extended analysis session to identify and agree the key themes and issues that had emerged. The themes and sub-themes were listed and then the transcripts were read again in detail and annotated to identify passages and quotes related to the themes. New themes were discussed among the researchers and added where appropriate.

\section{Eatwell week resource}

The resource was presented to focus group participants as a twenty-six page, A5 sized, spiral bound laminated

Table 1 Location and characteristics of consumer focus groups

\begin{tabular}{|c|c|c|c|c|}
\hline & $\begin{array}{l}\text { Dundee } \\
\text { (n } 9)\end{array}$ & $\begin{array}{l}\text { Salford } \\
(n 9)\end{array}$ & $\begin{array}{l}\text { Lewisham } \\
\quad(n 8)\end{array}$ & $\begin{array}{l}\text { Redditch } \\
\text { (n9) }\end{array}$ \\
\hline Age (years) & $16-24$ & $25-44$ & $35-59$ & $45-65+$ \\
\hline Socio-economic status* & C2DE & C2DE & $\mathrm{ABC} 1$ & $\mathrm{ABC} 1$ \\
\hline \multirow{3}{*}{ Employment status } & Full time: $n 3$ & Full time: $n 5$ & Full time: $n 5$ & Full time: $n 5$ \\
\hline & Part time: $n 2$ & Part time: $n 2$ & Part time: $n 3$ & Part time: $n 2$ \\
\hline & Not working: $n 4$ & Not working: $n 2$ & & Not working: $n 2$ \\
\hline Household income & Low & Low & Medium/high & Medium/high \\
\hline & $<£ 15999 \mathrm{pa}$ & $<£ 15999 \mathrm{pa}$ & $>£ 16000 \mathrm{pa}$ & $>£ 16000 \mathrm{pa}$ \\
\hline Cooking skills & Very littlet or not at all & At least moderate & Very littlet or not at all & At least moderate \\
\hline
\end{tabular}

*Participants were classified into one of the six social grades which are based on the current or previous occupation of the household's chief income earner. Groups $\mathrm{ABC} 1$ = professional, managerial and clerical occupations; groups C2DE = skilled and unskilled manual occupations and the economically inactive. tMost meals were ready meals, takeaways or food that only required re-heating.

¥Most meals cooked from scratch or from a mix of fresh and pre-prepared ingredients such as sauces. 
booklet. The booklet included seven menu pages each physically split into four horizontal sections (one each for breakfast, lunch, evening meal and additional foods/ snacks) which allowed meal options for each day to be interchangeable, to demonstrate the flexibility of the food choices within the week. The front page of each meal section showed a picture of the suggested meal with text alongside detailing the contents of the meal. The reverse provided details about the recipe ingredients and more general tips relevant to that particular meal or meal substitutions. Additional information and guidance was provided to assist users in implementing the eatwell week menu, including how to achieve macro- and micronutrient intakes if energy requirements were greater or less than those shown in the week. It was also highlighted that the eatwell week was based on everyday foods, regularly eaten in the UK. Users were advised that the eatwell week was not intended to be prescriptive: that the meals did not have to be eaten in the order shown in the booklet but could be mixed and matched. Possible substitutions/alternatives for some of the meals were given, plus information on how drinks which provide energy (including alcohol) would fit in to the week. To maximise flexibility, advice was given that the foods included in the eatwell week menu could be eaten at any point throughout the day. Advice was also included on:

1. How shopping/planning/storing food effectively could make implementing the eatwell week easier.

2. Maximum salt intake recommendations.

3. Fruit and vegetable recommendations.

4. Using food labels, in particular the FSA's front-of-pack labelling system.

5. Making healthier choices when eating out, in addition to advice on how to compensate for consuming too many high-fat and/or high-sugar foods.

6. Minimising waste.

7. Food safety, focusing on cooking, chilling, cleaning and prevention of cross-contamination.

\section{Results}

\section{Resource concept, presentation and style}

Consumers and health professionals felt that the introduction of a resource to improve the public's understanding of a balanced diet would be welcomed and fill a gap in current resources.

Initial reactions to the style and presentation of the resource were positive:

'This is quite quirky and modern. That is, less boring ... there is something to be said about the way it has been designed.' (Dietitian)

Most appealing to both consumers and health professionals were the split pages which helped convey the message that meals and snacks from different days were interchangeable. The inclusion of photographs increased engagement with the resource and was considered a useful guide in the preparation of meals. However, participants were drawn to these pages and often failed to read the introductory and supplementary text. This frequently left participants with questions which were answered within the booklet, e.g. the purpose of the resource or its intended users. Health professionals in particular felt it was unclear who the eatwell week was intended for and what was its purpose. The presentation of the text was also criticised by health professionals who felt it was too dense and that consumers would not attempt to read the supplementary information. While less critical of the text, some consumers felt that some of the language and terminology used in the introductory and supplementary text was too complex.

Interviews with adults from a low literacy class revealed that they struggled with words that could not be further simplified such as 'plate' and 'recipe'. The resource is therefore not likely to be suitable for individuals with significant literacy difficulties.

\section{Мепu}

Consumers reported that the eatwell week menu was realistic as it comprised largely foods that they recognised and that they already ate (although often in ready meal or takeaway format) as well as some 'treats'. There had been a preconception that it would contain more salad and vegetables than it did, which was interesting as the eatwell week exceeds the 5-a-day target for fruit and vegetables:

\section{'It's not all just vegetables and steamed fish.' (Health} professional)

'Never thought or expected to see apple crumble or chocolate biscuits.' (Female consumer)

However some consumers and health professionals felt that the menu was too prescriptive and did not offer enough flexibility. Health professionals, mainly in London, commented that the meals were very European and thus not suitable for many of the ethnic groups they worked with.

Initial reactions from some participants (particularly women) were that there was simply too much food included in the eatwell week. This held true for some after trying the menu:

'It just seems an awful lot, I don't eat breakfast or lunch.' (Female consumer)

'Well, I'd never get through four meals a day.' (Male consumer)

Some consumers and health professionals also felt there was too much bread and carbohydrate included.

Many consumers thought the between-meal snacks were to be consumed at the end of the day and, where two snacks were illustrated, this was interpreted as an 
either/or choice (which, in the case of portions of fruit, it was not). Some consumers felt bound by the specific fruits suggested rather than recognising that they could substitute them with the fruits they preferred.

\section{Consumer behaviour}

\section{Adberence to the menu}

Consumers who reported following the week closely reported an increased sense of well-being. Having eaten breakfast, which previously many had not done, some claimed to have consumed fewer fatty and/or sugary snacks, particularly mid-morning:

'Having yoghurt with fruit for breakfast, it cut out the chocolate Kit Kat that I normally have at midday.'

(Male consumer)

Even those who did not follow the week closely reported being influenced by the booklet when making decisions about what to eat while on the go or out socialising:

'It did make me think about what I ordered, so I ordered something that wasn't fried and that came with rice, so in a way it made me think about what I was eating.' (Female consumer)

\section{Barriers}

Cooking skills. Lack of cooking skills did not appear to be a significant barrier to using the eatwell week. Those who usually did not cook, or cooked very little, found the recipes easy to follow, 'do-able' and felt a sense of achievement having cooked from scratch:

'I felt like a gourmet chef.' (Female consumer)

The fact that the recipes did not have long, off-putting lists of ingredients was commented on positively. However, advice on how to include pre-prepared foods or takeaways in the week was also requested. Feedback was unanimous that recipes should be an integral part of the resource rather than something that had to be sought out from a website or another source.

Time. Time was highlighted by consumers as a barrier to healthy eating and many reported they did not eat three meals per day. Those who skipped breakfast said they were up too early to be ready to eat or that they simply did not have time to eat as well as get ready for work and get their families ready for the day. However there was also a view that, through practice and repeated use of the recipes, the time burden would be reduced:

'I found that doing this at first felt like a chore, getting up in the morning, doing my breakfast and then preparing lunch to take with me. But then as I went on it didn't seem so much of a chore. It felt more natural, fitting into my lifestyle. So after a while it would naturally just slot into place and I'd make more time, wake up that little bit earlier.'

(Female consumer)

Facilities. Lack of facilities to prepare either breakfast or lunch at work was frequently raised as a significant barrier and many wanted the inclusion of more 'packed lunch' or sandwich options to eat away from home.

Knowledge. The message of balance, flexibility and adaptability was central to the design of the eatwell week; however, many consumers lacked the requisite food knowledge to be able to make appropriate substitutions or adaptations to the meals which they did not want to eat. Consumers (particularly those from the lower socio-economic groups) frequently reported that they removed vegetables from meals/recipes but had not replaced them with preferred substitutes, or that the same meal was consumed on multiple occasions throughout the week. Health professionals expressed concern that because a food was included in the menu people may take the view that they could eat it as frequently as they chose.

Cost. While no detailed comparison of costs was made, the sense among consumers, following the trial period, was that the eatwell week menu was cheaper because they were buying fewer treats.

\section{Discussion}

Provision of additional tools to help individuals interpret and put into practice healthy eating dietary advice supports the UK and Scottish Governments' public health policies. The eatwell week was well received by consumers and health professionals and was viewed as filling a gap in existing resources. The colourful style of the eatwell week resource, with its split pages to illustrate the flexibility of the menu, was popular with consumers and has been used in other recently published and successful cookery books. However, it was an expensive format to produce, which may preclude publication of the resource in this form.

The decision to use Taylor Nelson Sofres data to guide the development of the eatwell week and thus ensure appropriateness for the UK population and increase acceptability was well founded. Consumer focus group participants were encouraged and reassured to see foods in the eatwell week they recognised and already included in their diets.

The resource was developed to be illustrative and not prescriptive, but perhaps was too reliant on the assumption that consumers would have sufficient knowledge/ability to choose alternatives if what was illustrated was disliked or unavailable. It was clear that some consumers lacked the requisite knowledge to adapt recipes. Clearer guidance was needed to encourage users to substitute food items for a preferred option rather than omit foods completely. 
Despite efforts to present the eatwell week as illustrative, it was still deemed too prescriptive by focus group participants. Consumers and health professionals felt that the provision of a greater number of specific alternatives to meals would enhance flexibility and continued use of the eatwell week and it is important that users can adapt and substitute meals to sustain use of the eatwell week. While being directed to specific alternatives could also be described as prescriptive, it was clear that specific direction was required due to a lack of knowledge/ability on the part of consumers. Sustained use of the eatwell week is an important goal; however, care needed to be taken with any suggested alternatives/alterations to the meals and recipes to ensure that Dietary Reference Values were still met and the scientific basis of the work was not undermined.

The concept of a nutritionally balanced food intake over the course of the week was not well understood, despite this being the main aim of the project. In some cases, as feared by the health professionals, certain foods/ meals were consumed more frequently than illustrated, which could unbalance macro- and micronutrient intakes. The eatwell week resource needed to communicate more clearly that the foods should only be consumed as frequently as illustrated and that this is particularly important for the more energy-dense, high-fat and/or high-sugar foods. This information is essential to enable users to consume a healthy balanced diet, a goal which is not achieved by the majority of the UK population ${ }^{(1-4)}$.

Deficits in the knowledge of both health professionals and consumers were highlighted, particularly in relation to the role of carbohydrates within a healthy diet. Percentage of energy from carbohydrate-rich foods in the eatwell week was close to the Dietary Reference Value of $50 \%$ of total energy intake on each day ${ }^{(7)}$. However, consumers and some health professionals felt that there was a lot, perhaps even too much, bread (and other carbohydrate) included in the eatwell week. For the general public this is likely, in part, to reflect a lack of knowledge and understanding of the composition of a healthy diet. The recent promotion of low-carbohydrate diets intended for weight loss may also have been incorrectly interpreted as healthy eating advice by the public $^{(8)}$.

Previous research has shown that health professionals have an understanding of the principles of eating for health and the requirement that carbohydrate provides about $50 \%$ of total energy intake ${ }^{(9)}$. However, the current project has highlighted that some health professionals do not recognise this in practice. The eatwell week resource needs to increase emphasis on the role of carbohydrates in a healthy diet. Inconsistent advice from health professionals is cited by the public as a barrier to healthy eating and the present work has highlighted the need for ongoing nutrition training and education of health professionals $^{(5,10,11)}$.
Lack of time has been frequently cited as a barrier to healthy eating ${ }^{(5,10,11)}$. The breakfasts and lunches included in the eatwell week were intended to be simple, easily prepared meals with minimal difficulty and time required for preparation. But barriers related to time and effort, such as lack of time to eat breakfast or to prepare a packed lunch, were still evident. Breakfast was frequently skipped, suggesting that the potential benefits of eating breakfast were not recognised ${ }^{(12)}$.

Difficulties making time to prepare a packed lunch plus a lack of facilities to heat/prepare foods at work suggest that for many there is a reliance on commercially pre-prepared sandwiches/foods. The eatwell week included a convenience/shop-bought lunch, yet consumers wanted more advice on how to include convenience foods, again suggesting a reliance on these products. Many of the lunches illustrated in the week could be prepared and taken to work. However, it was clear from the consumer feedback that more specific direction was required to highlight the ease with which these meals could be consumed outside the home.

Perceived time scarcity is also a driver to consuming 'ready meals', which are currently nutritionally chaotic ${ }^{(13)}$. This shift towards convenience meals, it is suggested, has eroded the cooking skills of many individuals, which is another barrier to healthy eating ${ }^{(14)}$. The evening meals included in the week were slightly more complex to prepare but required basic cooking skills only. Although the focus groups were set up to include those who did not cook often, lack of cooking skills was not found to be a significant barrier among consumers. Encouraging people to cook is an important factor in improving dietary habits and the simple recipes that accompanied the eatwell week seemed to help individuals overcome perceived difficulties with cooking, with those who usually cooked infrequently successfully following the recipes.

Promotion of how to make healthy meals quickly and cheaply is suggested as an effective way to address barriers to healthy eating in low-income groups ${ }^{(10)}$. The meals and snacks included in the eatwell week were designed to be affordable for those on low incomes, so that the advice could be used by all. In light of increases in food prices and of the cost of living as a whole, it was essential that consumers were provided with the tools to eat healthily according to their budget.

While the eatwell week suggests that vegetarians replace meat and poultry with vegetarian products, beans, pulses and additional fruit and vegetables, it was not developed to address the dietary requirements of ethnic minorities or other subgroups such as those who exclude all animal products from their diet.

\section{Post focus group revisions to the eatwell week resource}

The draft eatwell week resource was revised in light of focus group data. Specific revisions included the addition of a subtitle 'Putting Healthy Eating into Practice' on the 
front cover, to indicate the purpose of the eatwell week and introduce the concept of healthy eating as early as possible. In the introductory text, clear statements were made regarding who the week was for and the benefits of healthy eating on long-term health were emphasised. An additional split page was added which provided information on using the week. It was hoped this may overcome the problem of people overlooking the explanatory information as a result of being drawn immediately to the more interesting split pages.

Focus group participants had agreed that the resource would be more useful if full recipes were included. With the recipes added to the end of the resource, there was more scope within the split pages to provide healthy eating tips and other advice to support the eatwell week. The benefits of eating breakfast were highlighted and alternative options given for those who feel they cannot eat breakfast when they first get up. Specific tips were given on making the lunches easier to consume outside the home.

The supplementary/additional information was re-worded, presented more concisely and in a question-and-answer format that was divided into the following questions:

1. Will there be enough for me to eat?

2. What if I need to eat more or less than shown?

3. Why is there a lot of bread, pasta, potatoes and rice in the week?

4. What about drinks?

5. What about alcohol?

New information was provided on fish and meat (in light of the Scientific Advisory Committee on Nutrition's Iron and Health report) ${ }^{(15)}$ and information on salt, meal plans and shopping, eating out, food labels and food safety was re-worded to ensure clarity and brevity.

No changes were made to the foods and drinks included; however, more alternatives/substitutions to the illustrated meals were given to increase flexibility and encourage implementation of healthy eating beyond the week. Advice that each evening meal should be eaten only once over the course of a week was included, as was advice that foods such as chocolate, crisps and biscuits could be included in a healthy diet albeit less often and in smaller amounts, as illustrated in the resource.

As the recipes were now included within the booklet, tips were added alongside the recipes on how to modify them to extend the use of the eatwell week. Suggested meal alternatives and modifications to recipes were kept as close as possible to the original meal/recipes so that the nutritional composition of the menu was not altered significantly.

\section{Conclusion}

The eatwell week resource has endeavoured to address some of the known barriers to healthy eating. Consumer testing was a crucial element in its development and facilitated an informed and focused revision of the resource. It shows promise as a resource to support implementation of the principles of the eatwell plate and supports government priorities and policies for health.

Further research was required to explore the perceptions of health professionals and consumers with regard to healthy eating messages before the resource was ready to be used by both groups. This work has been undertaken $^{(8)}$ and the FSA in Scotland has made the eatwell week available online as the eatwell everyday website (www.eatwelleveryday.org) as part of its continued promotion of the eatwell plate.

\section{Acknowledgements}

Sources of funding: The eatwell week project (S14048/ FS424017) was funded by the FSA in Scotland. Conflicts of interest: The authors declare no conflict of interest. Ethics: Ethical approval was not required. Authors' contributions: The study was designed by W.S.L., M.E.J.L. and C.R.H. Focus group testing and data analysis were carried out by L.M. and J.E. All authors critically reviewed the manuscript.

\section{References}

1. Barton KL, Wrieden WL, Armstrong J et al. (2011) Estimation of food and nutrient intakes from Expenditure and Food Survey \& Living Costs and Food Survey Data in Scotland 2001-2009. http://www.foodbase.org.uk// admintools/reportdocuments/418-1-1141_S14035_Monitoring_ Report_2001-2009_310311final.pdf (accessed June 2013).

2. Department of Health (2011) National Diet and Nutrition Survey: Headline results from Years 1 and 2 (combined) of the Rolling Programme, 2008/9-2009/10. http:// www.dh.gov.uk/en/Publicationsandstatistics/Publications/ PublicationsStatistics/DH_128166 (accessed June 2013).

3. The Scottish Government (2012) The Scottish Health Survey 2011, Volume 1: Adults. http://www.scotland. gov.uk/Resource/0040/00402630.pdf (accessed June 2013).

4. Health \& Social Care Information Centre (2011) Health Survey for England - 2010, Trend tables. http://www.hscic. gov.uk/pubs/hse10trends (accessed June 2013).

5. National Obesity Observatory (2011) Knowledge and attitudes towards health eating and physical activity: what the data tell us. http://www.noo.org.uk/uploads/doc/ vid_11171_Attitudes.pdf (accessed June 2013).

6. Department of Health (1991) Dietary Reference Values for Food, Energy and Nutrients for the United Kingdom. London: HMSO.

7. Leslie WS, Comrie F, Lean MEJ et al. (2013) Designing the eatwell week: the application of eatwell plate advice to weekly food intake. Public Health Nutr 16, 795-802.

8. Chan V, Eunson J, Murray L et al. (2012) Food Standards Agency in Scotland research report: Investigating how both consumers and health professionals understand healthy eating messages. http://www.foodbase.org.uk//admintools/ reportdocuments/753-1-1294_FS244029_1_Ipsos-_FINAL.pdf (accessed June 2013).

9. Hankey CR, Eley S, Leslie WS et al. (2004) Eating habits beliefs, attitudes and knowledge among health professionals regarding the links between obesity, nutrition and health. Public Health Nutr 7, 337-343. 
10. O'Neill M, Rebane D \& Lester C (2004) Barriers to healthier eating in a disadvantaged community. Health Educ J 63, 220-228.

11. Lappalainen R, Saba A, Holm L et al. (1997) Difficulties in trying to eat healthier: descriptive analysis of perceived barriers for health eating. Eur J Clin Nutr 51, Suppl. 2, S36-S40.

12. Gibson SA \& Gunn P (2011) What's for breakfast? Nutritional implications of breakfast habits: insights from the NDNS dietary records. Nutr Bull 36, 78-86.
13. Celnik D, Gillespie L \& Lean MEJ (2012) Time-scarcity, ready meals, ill health and the obesity epidemic. Trends Food Sci Technol 27, 4-11.

14. Agri-Food Trade Service (2010) Consumer Trend Report, Convenience. http://www.ats-sea.agr.gc.ca/inter/5527-eng.htm (accessed June 2013).

15. Scientific Advisory Committee on Nutrition (2010) Iron and Health. London: TSO; available at http://www.sacn.gov. $\mathrm{uk} / \mathrm{pdf}$ /sacn_iron_and_health_report_web.pdf 